\title{
Epidemiological Characteristics of COVID-19 Infection in the Republic of Srpska: a Hundred Days Survey
}

\author{
Jela Aćimović, ${ }^{1,2}$ Ljubica Jandrić, ${ }^{1}$ Jelena Đakovic Dević, ${ }^{1}$ Janja Bojanić, ${ }^{1,2}$ Branka
} Subotić, ${ }^{1}$ Tina Radojčić, ${ }^{1}$ Nina Rodić Vukmir, ${ }^{1,2}$ Branislav Zeljković1

\begin{abstract}
Background/Aim: The World Health Organization (WHO) declared the spread of a novel disease COVID-19 as a pandemic on 11 March 2020. As of 12 June, there have been more than 7.4 million COVID-19 cases and more than 418,000 COVID-19 deaths globally. This paper represents epidemiological analysis of the first 100 days of COVID-19 epidemic in the Republic of Srpska.

Methods: Data of all COVID-19 cases confirmed in the Republic of Srpska between 4 March and 12 June were collected from epidemiological and laboratory testing reports obtained from the Public Health Institute of the Republic of Srpska. This cross-sectional analysis was carried out on a sample of 1,607 laboratory-confirmed COVID-19 cases, which included: summary of patient characteristics, examination of age distributions and sex ratios, calculation of case fatality and mortality rates, incidence rates analysis, epidemiological curve construction and subgroup analysis.

Results: Over 100 days after the first case was confirmed, the total number of infected patients in the Republic of Srpska rose to 1,607 (31,471 persons had been tested). As of 12 June, $69.9 \%$ of those cases has recovered. During that period there were 117 confirmed deaths (average age 72 years; $60.7 \%$ males; $86 \%$ older than 60 years; 94 $\%$ with at least one comorbidity). The sex ratio among the confirmed cases was $0.95: 1$ ( $48.7 \%$ men vs $51.3 \%$ women). Infections were less common in persons below 20 years of age (7.3\% of all confirmed cases) and the majority of the affected persons were in the group 40-69 years of age. As much as $86 \%$ of all death cases occurred in persons older than 60 years (average age 72 years) and $94 \%$ of all death cases had at least one underlying condition (mostly cardiovascular diseases, $79.5 \%$ ).

Conclusion: Evaluating the clinical data of COVID-19 patients, finding the source of infection and studying the behavior of the disease is crucial for understanding of the pandemic.
\end{abstract}

Key words: SARS-CoV-2, COVID, epidemic, epidemiology, analysis.
(1) Public Health Institute of the Republic of Srpska, Banja Luka, the Republic of Srpska, Bosnia and Herzegovina.

(2) Faculty of Medicine, University of Banja Luka, Banja Luka, the Republic of Srpska, Bosnia and Herzegovina.
Correspondence:

JELA AĆIMOVIĆ

E: jela.acimovic@gmail.com

\section{ARTICLE INFO}

Received: 25 June 2020 Revision received: 28 June 2020 Accepted: 29 June 2020

\section{Introduction}

In December 2019, the newly identified severe acute respiratory syndrome coronavirus 2 (SARS-CoV-2) emerged in Wuhan, China, causing COVID-19, a respiratory disease presenting mostly with fever, cough and, very often, with pneumonia. ${ }^{1,2}$ The disease spread rapidly to other parts of China and then to other countries around the globe. The first cases in Europe were reported on 24 January 2020 in France.

The WHO Director General declared spread of COVID-19 as a Public Health Emergency of Inter-

Copyright $\odot 2020$ Aćimović et al. This is an open access article distributed under the Creative Commons Attribution License (CC BY), which permits unrestricted use, distribution, and reproduction in any medium, provided the original work is properly cited. This article should be cited as follows: Aćimović J, Jandrić Lj, Đaković Dević J, Bojanić J, Subotić B, Radojčić T, et al. Epidemiological characteristics of COVID-19 infection in the Republic of Srpska: a hundred days survey. Scr Med 2020;51(2):74-80. 
national Concern (PHEIC) on 30 January and, in view of the severity of the disease spread, as pandemic on 11 March 2020. According to the statistics of the WHO and the European Centre for Disease Control (ECDC), as of 12 June, there were more than 7.4 million COVID-19 cases and more than 418,000 COVID-19 deaths globally. ${ }^{3}$

In January and February, while the public focus of attention was on China, the number of new cases and fatalities worldwide increased day by day. At that time the Republic of Srpska was in the first of four epidemiological scenarios of potential COVID-19 outbreak, in which there were no confirmed cases, but it was necessary to undertake numerous activities in order to increase the level of preparedness and to be ready to respond properly in order to identify and manage the new cases of COVID-19 infection. ${ }^{4}$ The first activities, led by the Public Health Institute of the Republic of Srpska (PHI RS), were aimed at setting-up the system for continuous monitoring of the epidemiological situation, as well as providing accurate information to the health authorities and general public related to SARS-CoV-2 onset and spread of the disease, the characteristics of the virus and the disease itself and recommending prevention measures to the whole population. The Ministry of Health and Social Welfare of the Republic of Srpska established coordination mechanisms to conduct activities pertaining to the outbreak of the novel coronavirus. Two medical faculties, Banja Luka (University of Banja Luka) and Foča (University of East Sarajevo), participated in providing adequate information to the public, through the established COVID-19 call centres. At that stage, it was necessary to undertake precaution measures at points of country border entry, with an aim of early detection of infected persons. At the same time, the PHI RS rapidly developed the set of guidance for healthcare system preparedness for the emergence of COVID-19 in the Republic of Srpska.

At the first phase, primary healthcare centres conducted the health surveillance of travelers arriving in the Republic of Srpska and at the same time prepared new protocols and trained staff to respond to the emergence of the novel virus. The hospitals prepared action plans for hospitalisation, isolation, and treatment of patients in infectious disease clinics and intensive care units. The capacities of two accredited laboratories in the Republic of Srpska have been strengthened for the reverse transcription polymerase chain reaction (RT-PCR) detection of the SARS-CoV-2 virus. Numerous activities have been undertaken to improve public health preparedness, as well as preparedness of other sectors, before the importation of the first cases of COVID-19 disease.

The aim of this study was to evaluate the epidemiological characteristics of the COVID-19 infection in the Republic of Srpska for the first 100 days of the infection outbreak.

\section{Methods}

This study was carried out retrospectively in the Republic of Srpska, which is one of two administrative entities in Bosnia and Herzegovina. The population of the Republic of Srpska is 1.2 million. All data of COVID-19 cases in the Republic of Srpska between 4 March and 12 June were obtained from epidemiological and laboratory reports of the PHI RS. Epidemiological data were obtained through the surveillance system (mandatory notification of the occurrence of cases of the selected infectious diseases). Data on laboratory tests (RT-PCR assays for the detection of SARSCoV-2) were obtained from two microbiological laboratories, one at the University Clinical Centre of the Republic of Srpska (UCC RS), for testing of patients hospitalised or examined at the UKC RS and the second one at the PHI RS, for all other suspected cases in the Republic of Srpska. Only laboratory-confirmed cases were included in this study. This analysis was carried out on a sample of 1,607 laboratory-confirmed COVID-19 cases. Analyses included: summary of patient characteristics, age and sex ratios, case fatality and mortality rates, incidence rates analysis, epidemiological curve construction and subgroup analysis. All data were analysed using SPSS, statistical program for social sciences and the basic descriptive statistics was used for presentation of the results.

\section{Results}

One hundred days after the outbreak of COVID-19, the total number of confirmed cases in the Republic of Srpska was 1,607 (out of 31,471 people tested) and by the time 1,123 (69.9\%) of those cases have been already recovered. Among those infect- 
Table 1: The major characteristics of COVID-19 infected cases in Republic of Srpska on 12 June, 2020

\begin{tabular}{|c|c|c|}
\hline Cases, characteristics & $\mathbf{n}$ & $\%$ \\
\hline Number of infected patients & 1,607 & \\
\hline Cumulative incidence rate/100.000 & 140.3 & \\
\hline Age in years, median & 52.3 & \\
\hline (range) & $(0.5-96)$ & \\
\hline Female & 825 & 51.3 \\
\hline Male & 782 & 48.7 \\
\hline \multicolumn{3}{|l|}{ Age groups (years) } \\
\hline $0-9$ & 45 & 2.8 \\
\hline $10-19$ & 72 & 4.5 \\
\hline $20-29$ & 178 & 11.1 \\
\hline $30-39$ & 217 & 13.5 \\
\hline $40-49$ & 249 & 15.5 \\
\hline $50-59$ & 272 & 16.9 \\
\hline $60-69$ & 235 & 14.6 \\
\hline $70-79$ & 192 & 11.9 \\
\hline$\geq 80$ & 147 & 9.1 \\
\hline Healthcare workers & 109 & 6.8 \\
\hline Recovered & 1123 & 69.9 \\
\hline Number of active cases & 367 & 22.8 \\
\hline
\end{tabular}

ed, 782 (48.7\%) were man and 825 (51,3\%) were women. The median age of patients was 52.3 years (range, $0.5-96$ years; Table 1 ).

The number of confirmed cases differed by age. Most of the cases were in the age group 50-59 years (272 persons or $16.9 \%$ of the total number of cases), and then in 40-49 (15.5\%) and 60-69 $(14.6 \%)$ age groups. The youngest person with confirmed SARS-CoV-2 infection was 6 months old and the oldest one was 96 years old (median 52). The total number of confirmed cases among children aged 0-9 years was 45 , which accounts for 2.8 $\%$ of all confirmed cases. A total of 109 health care workers suffered from the infection, representing the $6.8 \%$ of all cases. (Table 1, Figure 1).

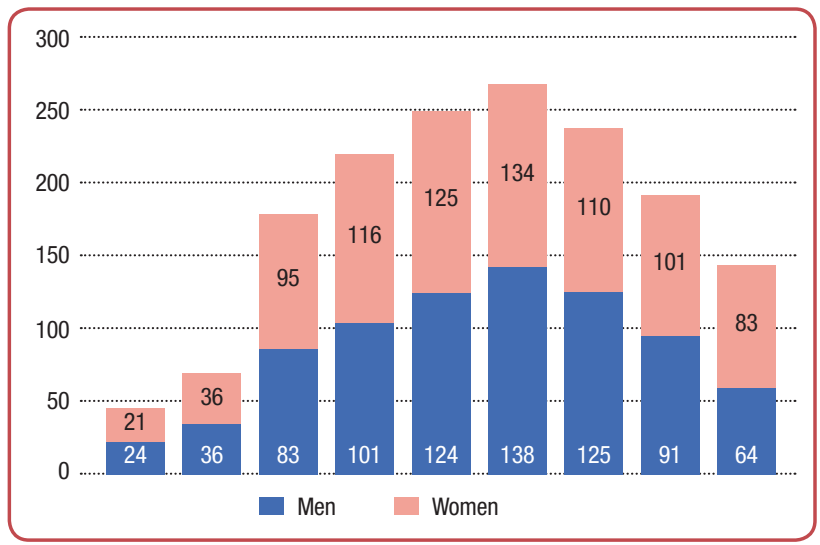

Figure 1:Age/sex distribution of COVID-19 cases in the Republic of Srpska presented in age groups.

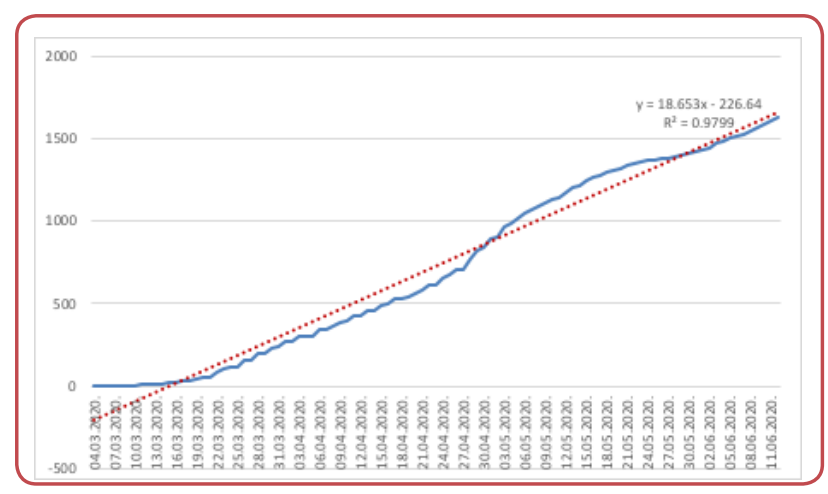

Figure 2: The cumulative number of confirmed COVID-19 cases in the Republic of Srpska during the 100 days after the first case was detected on 4 March 2020.

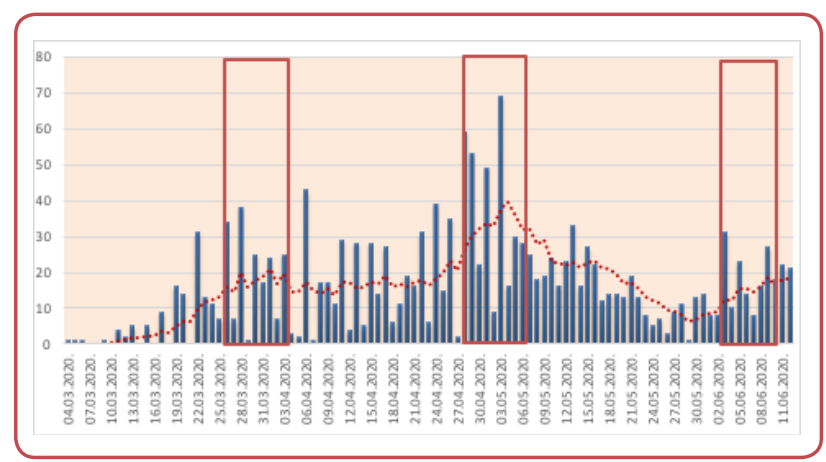

Figure 3: Daily number of COVID-19 cases in the Republic of Srpska (blue bars) and 7-day moving average trend line (dashed red line) by the June 12. The red rectangles represent the first (I), second (II) and third (III) peaks of significantly higher number of cases.

The epidemiological curve of cumulative number of cases in the Republic of Srpska indicates a moderate linear growth pattern (Figure 2). Although the number of cases has grown substantially, there were three peaks with significantly higher number of cases. The first one was observed between 25 March and 3 April with the number of 30-40 infected cases/day. The second peak was recorded at the last week of April with an average number of 40-66 confirmed cases/day, and the third one started at the beginning of June (Figure 3).

The cumulative incidence rate on 12 June was 140.3 cases per 100,000 inhabitants (HTI) which is significantly higher than in the whole Bosnia and Herzegovina (86/HTI). There were three significant increases in incidence rates/HTI per week; the first one was observed on week 4 with 11.27/HTI, the second one started on week 7 and continued for the following five weeks, reaching the peak on the week 9 with 21.66/HTI and the third one had begun to rise at the second week of June (13.71/HTI; Figure 4). The mortality rate per HTI was usually below 1 , but during the weeks 


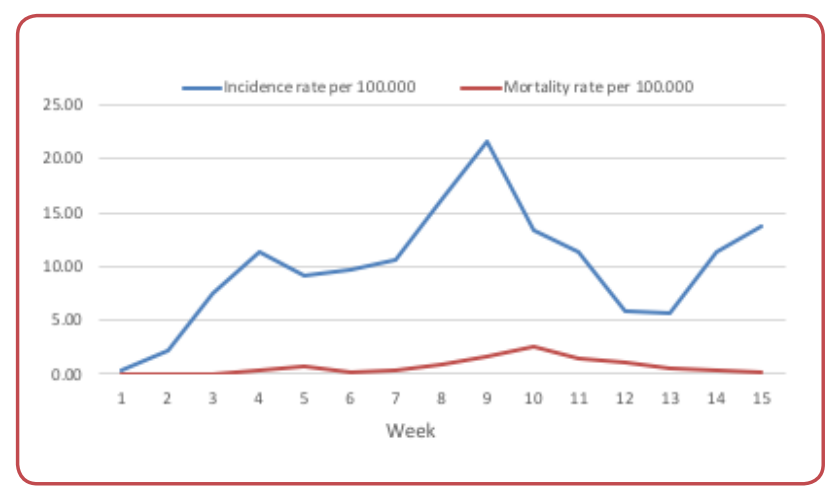

Figure 4: Weekly incidence and mortality rates of COVID-19 in the Republic of Srpska, starting from March 4th.

9-12 it significantly increased reaching the maximum of 2.62/HTI on week 10 (Figure 4).

In the South East European (SEE) Region, the highest cumulative incidence rate, recorded at the beginning of June, was in Serbia (165/HTI) and the lowest in Bulgaria (36/HTI) and Greece (28/HTI). However, well developed western countries, such as the USA and the EU countries (Italy, Spain, Belgium, UK, Sweden etc.) had scored 5-10 times higher incidence rates comparing to countries of SEE (Figure 5).

The first death case from COVID-19 in the Republic of Srpska was registered on 28 March, or 24 days after the first case was confirmed. Since that

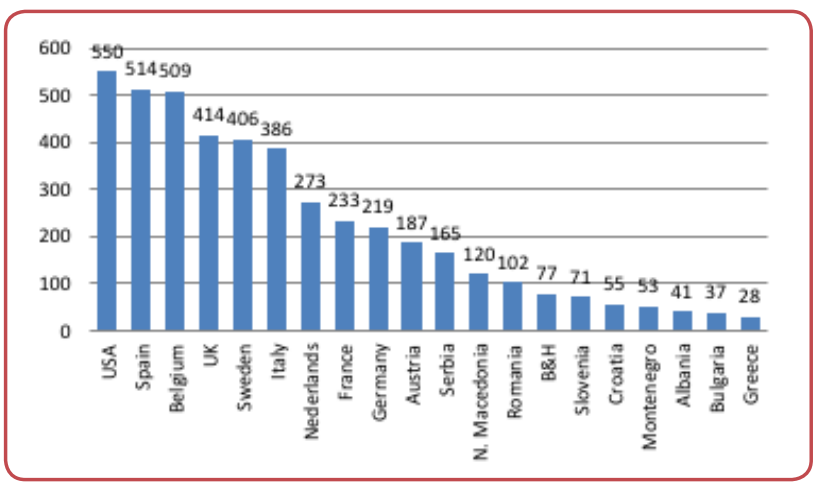

Figure 5: The comparison of cumulative incidence rates (number of cases per 100,000 inhabitants) of USA and some west European countries with east European countries.

time 117 people died due to the COVID-19. That represents a mortality rate of 101 per million inhabitants. Similar to the cumulative incidence rates, west European countries have had significantly higher mortality rates, comparing to countries of SEE (Figure 6).

Characteristics of COVID-19 death cases in the Republic of Srpska are described in the Table 2. The youngest patient who died due to COVID-19

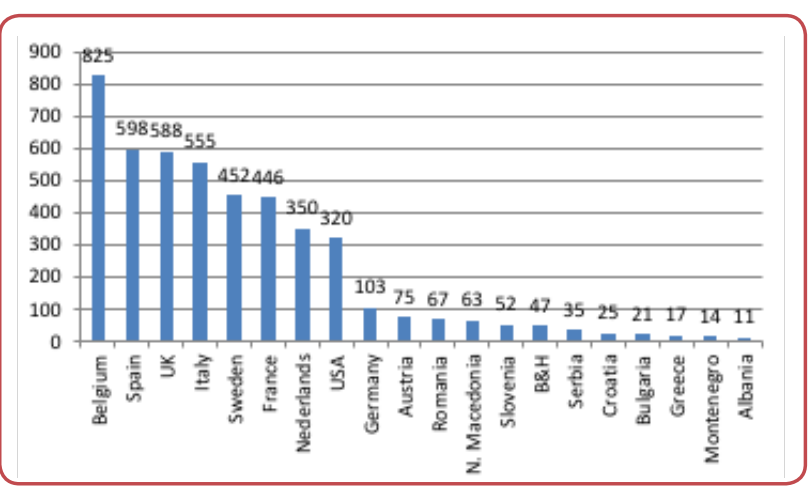

Figure 6: Comparison of cumulative mortality rates (number of death cases per million inhabitants) of some western European countries with eastern European countries.

infection was a 26 years old man with the Down syndrome, and the oldest was aged 96 , with the median and average age among death cases of 72 years. Almost all (94\%) persons who died from COVID-19 infection had at least one comorbidity. The most common comorbidities belonged to cardiovascular diseases $(79,5 \%$ of all death cases; mainly hypertension) and diabetes (32,5\%). Data suggest that sex and age can also be considered as risk factors for COVID-19 related deaths. As much as $60.7 \%$ of death cases were male (Ta-

Table 2: Major characteristics of COVID-19 related death cases in the Republic of Srpska by the June 12.

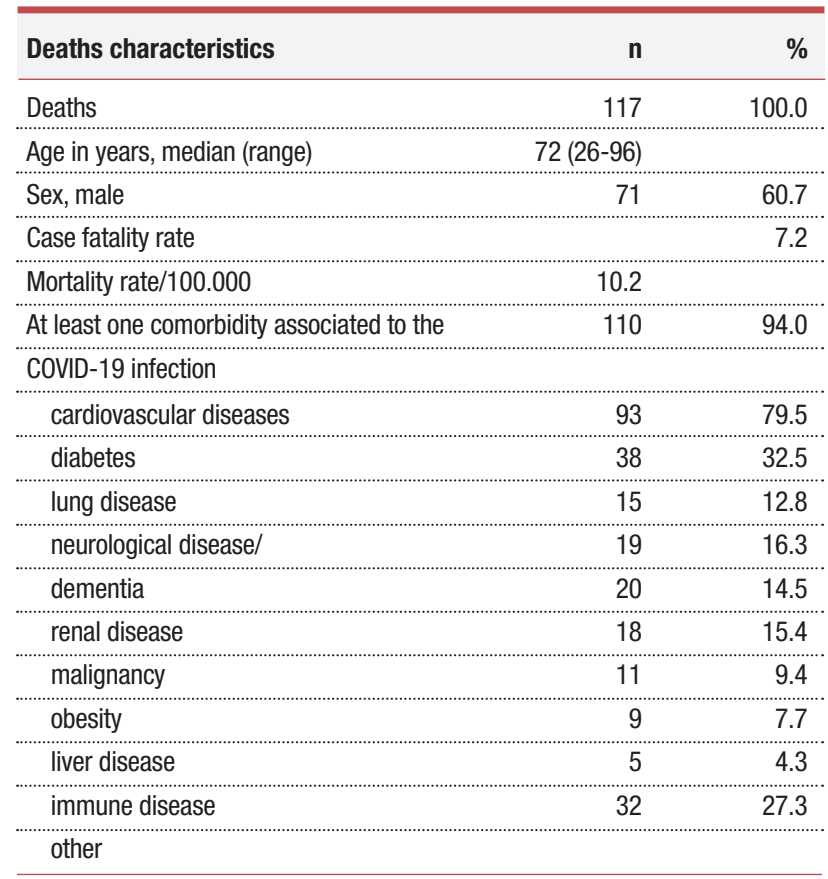

ble 2). The case fatality rate was $7.2 \%$ and it was higher in men than in women; $9.1 \%$ of men who contracted the COVID-19 infection died, comparing to $5.6 \%$ of women. The difference is even higher in the age group $\geq 80$ years, in which $36 \%$ of men who contracted the virus died, comparing 


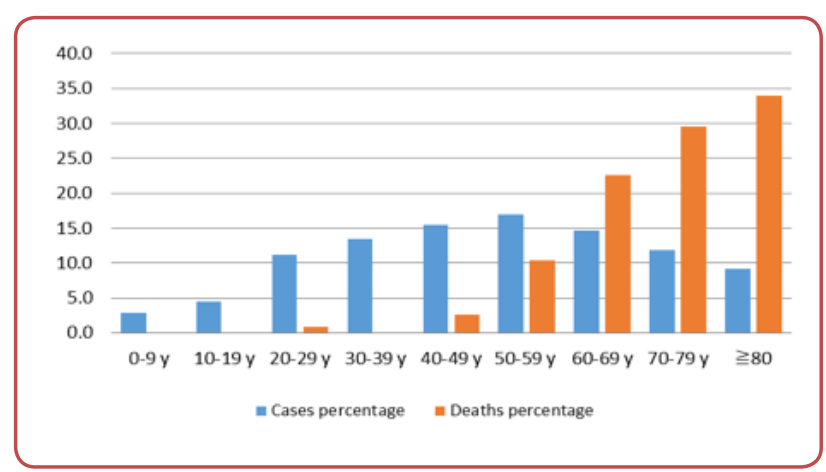

Figure 7: Percentage of COVID-19 infection cases $(N=1607)$ and deaths cases $(\mathrm{N}=117)$ by age groups in the Republic of Srpska during 100 days of epidemic.

to $20 \%$ of fatal outcomes among women from the same age group.

Age-specific case fatality rate was getting higher with the increase in age. The highest number of confirmed infection cases was within the age group 50-59 years, followed by the $40-49$ and 6069 age groups, but the highest number of deaths was among people aged $\geq 80$, followed by the age groups 70-79 and 60-69 (Figure 7). The oldest age group represents only $9.8 \%$ of all confirmed COVID-19 cases but comprised $34 \%$ of all death cases (Figure 7).

\section{Discussion}

The first case of COVID-19 in the Republic of Srpska was confirmed on 4 March in the City of Banja Luka. That was a 43-year-old man who arrived from Italy and developed mild symptoms of the disease. Soon thereafter he was hospitalised at the University Clinical Centre of the Republic of Srpska. ${ }^{2}$ Immediately after the laboratory test confirmed the SARS-CoV-2 infection, the epidemiologists from Banja Luka Health Centre started contact tracing, which is a critically important tool in counter-epidemic response..$^{4-6}$ All family members of the first patient, although asymptomatic, were promptly tested and the infection was confirmed in his 13-year-old son. In order to limit further transmission of the disease, the elementary school the boy attends was closed and disinfected and all children and teachers who were in contact with the boy were home-quarantined and tested. All measures were taken on time and no one from the school was infected.
At the same time, by tracing other contacts of the first patient, the infection was confirmed in a 46-year-old man from the neighbouring municipality of Čelinac, who also arrived from Italy in the same car with the first patient and then in his 17-year-old daughter. Among their numerous contacts, including girl's classmates and schoolteachers, there were no new infections. The first cluster in the Republic of Srpska was closed with only four people infected.

However, new imported cases very soon led to a greater spread of the disease. Like in other countries, transmission mostly occurred at social gatherings, with the important role of some super-spreading events, as well as at home and work settings, which directed us to the following epidemiological phases: phase of sporadic cases, clusters of cases and the phase of community transmission. ${ }^{14-6}$ Moving from phase to phase, public health response had to be adjusted in order to achieve the main goals: to slow down and stop transmission, prevent outbreaks and delay spread, provide optimised care for all patients, especially the seriously ill, and to minimise the impact of the epidemic on health systems, social services and economic activity. ${ }^{7}$

The Republic of Srpska was among the first countries in the region which, after the occurrence of local transmission of COVID-19, promptly introduced interventions on 10 March to suppress the spread of the virus, such as closing of schools, public places, restriction of public gatherings and border restrictions, advising citizens to work from home whenever is possible. Contact tracing followed by quarantine and isolation was carried out whenever new cases were identified. The purpose of these measures was to slow down the spread of the disease, and by controlling the infection to get "flattened the epidemic curve". Countries that had implemented the "lockdown" measures in earlier phases of the COVID-19 outbreak had lower incidence and mortality rates. ${ }^{8}$ Despite all epidemiologic measures the virus spread rapidly and the City of Banja Luka has become the biggest COVID-19 cluster in the Republic of Srpska and the whole Bosnia and Hezegovina with more than $50 \%$ of all cases.

One hundred days after the first case was confirmed, 31,671 people had been tested for COVID-19 in the Republic of Srpska, and 1,607 
have been found positive (5.1\%). Among those positive, the proportion of females had a slightly higher rate $(51.3 \%)$ compared with males (48.7 $\%)$. Similar observations were reported in other studies. ${ }^{9-11}$ The mean age of patients was 52.3 and $47 \%$ of patients were from the age group 40-69, but older males and those with comorbidities, such as hypertension and diabetes, were more likely to have very severe symptoms and with the higher risk of death. As much as $86 \%$ of all death cases occurred in persons older than 60 (average age of death cases was 72 ). A total of $34 \%$ of all death cases were from the group of patients over 80 years and that group represented only $9.8 \%$ of all COVID-19 cases. These findings are consistent with other studies from China suggesting a higher fatality rate among men compared to women. ${ }^{9,12}$ There is no clear explanation for this difference, but it is possible that men had higher proportion of comorbidities than women. On the other hand, younger people were less likely to get infection than the older ones. ${ }^{13}$ As much as $94 \%$ of all death cases in the present study had at least one chronic comorbidity (mostly cardiovascular diseases, $79.5 \%$ ), which is in accordance with systematic reviews that have shown that people with chronic comorbidities like hypertension, other cardiovascular disease or diabetes are at higher risk of progressing to more severe COVID-19 disease and death. $^{14}$

There were 107 healthcare workers in this study that suffered SARS-CoV-2 infection, representing $6.8 \%$ of all cases. Reports are different from different countries, ranging from $2.8 \%$ in Iran, ${ }^{11}$ $4.6 \%$ in Wuhan (China), ${ }^{9} 14 \%$ in England ${ }^{15}$ to $19.9 \%$ in Kazakhstan. ${ }^{16}$ The reason for obviously higher case rate in health care workers could be explained by initial lower awareness, shortage of medical resources and inadequate use of personal protective equipment, as well as the higher exposures to infected patients at the early stage of epidemic.

Timely implementation of measures in the Republic of Srpska was of utmost importance for epidemiological curve of cumulative number of cases indicating moderate linear growth pattern. In the last week of April, after a month and a half after the first COVID-19 case was confirmed, the Republic of Srpska faced a more intensive increase of number of cases, compared to the previous trend. The incidence rate per week was $21.66 /$ HTI. By recognising the problem and after strengthening of infection prevention and control measures the number of cases declined and the epidemiological curve has gradually returned to the previous trend. Several factors have influenced that increase, among which are the occurrence of hospital-associated infections and the fact that infection had spread in long-term care facilities. It has been shown that virus can easily enter into the hospital settings and long-term care facilities and spread among vulnerable population, particularly elderly and people with chronic diseases. ${ }^{17}$ According to the European Centre for Disease Prevention and Control (ECDC) the reported deaths in long-term care facilities account for $30-60 \%$ of all COVID-19 deaths in many European countries. ${ }^{18}$

Since 11 January 2020, when the first death case caused by COVID-19 was reported in China, the disease has become one of the leading infectious causes of death in number of countries around the world, with the total of 418.302 reported deaths globally, as of 12 June 2020 . Although it is not possible to predict long term death toll of COVID-19, due to the ongoing nature of the pandemic, with an average of 2,300 deaths daily, it currently represents the third deadliest communicable disease, trailing tuberculosis and hepatitis and leaving behind pneumonia, HIV/AIDS, malaria, seasonal flu and all other vaccine-preventable communicable diseases. ${ }^{19}$

The developed countries, such as the USA and the EU countries, have experienced significantly higher cumulative incidence and mortality rates, comparing to SEE countries. There are no explanations for these facts, but some reports emphasised that the drastic social isolation measures, undertaken especially in Eastern European countries might contribute to these differences.6 Once the pandemic become over, it will be possible to make more specific analyses and to understand all the possible reasons why the SEE countries have provided better response to the first wave of COVID-19 pandemic, compared to developed EU countries.

By 12 June 2020, as much as 1,123 infected persons have recovered, representing $69.9 \%$ of all infected cases in the Republic of Srpska. The number of active cases is $367(22.83 \%)$ and the epidemic is still far from fading out. 


\section{Conclusion}

It is clear that all age groups are susceptible to COVID-19, but older males and those with comorbidities are more likely to develop severe form of disease. Even though COVID-19 is highly contagious, control measures have proven to be very effective and public health interventions were temporally associated with improved control of the COVID-19 outbreak. Evaluating the clinical data of COVID-19 patients, finding the source of infection and studying the behavior of the disease is crucial for understanding of the pandemic.

\section{References}

1. Milovanović DR, Janković SM, Ružić Zečević D, Folić M, Rosić N, Jovanović D, et al. [Treatment of coronavirus disease (COVID-19)]. Med Čas 2020;54(1). DOI: https:// doi.org/10.5937/mckg54-25981. [Online First]. Serbian.

2. Mijović B. COVID-19 - lessons learned. Scr Med 2020;51(1):1-5.

3. European Centre for Disease Prevention and Control. COVID-19 situation for the EU/EEA and the UK, as of 27 June 2020. Available from: www.ecdc.europa.eu. Accessed on: 27 June 2020.

4. World Health Organization. Critical preparedness, readiness and response actions for COVID-19, interim guidance: World Health Organisation; 2020. Available from: https://www.who.int/publications/i/item/ critical-preparedness-readiness-and-response-actions-for-covid-19. Accessed on: 24 June 2020.

5. Adam D, Wu P, Wong JY, Lau EHY, Tsang TK, Cauchamez $\mathrm{S}$, et al. Clustering and superspreading potential of severe acute respiratory syndrome coronavirus 2 (SARSCoV-2) infections in Hong Kong. Res Square May 2020. doi:10.21203/rs.3.rs-29548/v1

6. Al-Tawfic JA, Rodriguey Morales AJ. Super-spreading events and contribution to transmission of MERS SARS, and SARS-CoV-2 (COVID-19). J Hosp Infect 2020 Jun;105(2):111-2.

7. World Health Organization. Strategic preparedness and response plan. 2019 Novel Coronavirus (2019-nCoV) Geneva: WHO; 2020. Available from: https://www.who. int/docs/default-source/coronaviruse/srp-04022020. pdf?ua=1. Accessed: 24 June 2020.

8. Ylli A, Wu YY , Burazeri G, Pirkle C, Sentell T. The lower COVID-19 related mortality and incidence rates in Eastern European countries are associated with delayed start of community circulation. medRxiv preprint doi: https://doi.org/10.1101/2020.05.22.20110148. This version posted 26 May 2020.

9. Pan A, Liu L, Wang C, Guo H, Hao X, Wang Q, et al. Association of public health interventions with the epidemiology of the COVID-19 outbreak in Wuhan, China. JAMA 2020;323(19):1915-23.

10. Wang D, Hu B, Hu C, Zhu F, Liu X, Zhang J, et al. Clinical characteristics of 138 hospitalized patients with 2019 novel Coronavirus-infected pneumonia in Wuhan, China. JAMA 2020; 323(11):1061-9.

\section{Acknowledgements}

None.

\section{Conflict of interest}

None.

11. Shahriarirad R, Khodamoradi Z, Erfani A, Hosseinpour H, Ranjbar K, Yasaman Emami Y, et al. Super-spreading Events and Contribution to Transmission of MERS, SARS, and SARS-CoV-2 (COVID-19). J Hosp Infect 2020 Jun;105(2):111-2.

12. Wu Z, McGoogan JM. Characteristics of and important lessons from the coronavirus disease 2019 (COVID-19) outbreak in China: summary of a report of 72314 cases from the Chinese Center for Disease Control and Prevention. JAMA 2020;323(13):1239-42.

13. The Novel Coronavirus Pneumonia Emergency Response Epidemiology Team. Vital surveillances: the epidemiological characteristics of an outbreak of 2019 novel coronavirus diseases (COVID-19)—China, 2020. China CDC Weekly 2020;2:113-22.

14. Yang J, Zheng Y, Gou X, Pu K, Chen Z, Guo Q, et al. Prevalence of comorbidities and its effects in patients infected with SARS-CoV-2: a systematic review and meta-analysis. Int J Infect Dis 2020 May 1;94:91-5.

15. Hunter E, Price DA, Murphy E, van der Loeff IS, Baker KF, Lendrem D, et al. First experience of COVID-19 screening of health-care workers in England. Lancet 2020 May 2;395(10234):e77-e78. doi: 10.1016/S01406736(20)30970-3.

16. Maukayeva S, Karimova S. Epidemiologic character of COVID-19 in Kazakhstan: a preliminary report. North Clin Istanb 2020;7(3):210-13.

17. Logar S. Care home facilities as new COVID-19 hotspots: Lombardy Region (Italy) case study. Arch Gerontol Geriatr 2020 Jul-Aug;89:104087. doi: 10.1016/j.archger.2020.104087

18. ECDC Public Health Emergency Team, Danis K, Fonteneau L, Georges S, Daniau C, Bernard-Stoecklin S, Domegan L. High impact of COVID-19 in long-term care facilities, suggestion for monitoring in the EU/EEA, May 2020. Euro Surveill 2020 Jun 4;25(22):pii=2000956. doi: 10.2807/1560-7917.ES.2020.25.22.2000956

19. Covid-19-coronavirus-infographic-datapack. Available from: https://informationisbeautiful.net/visualizations/covid-19-coronavirus-infographic-datapack/. Accessed: 20 June 2020. 